\title{
Roles of Toll-Like Receptor 3 in Human Tumors
}

\author{
Xin Zheng ${ }^{*}$, Song $L_{i}^{*}$ and Hui Yang * \\ Department of Neurosurgery, Xinqiao Hospital, Army Medical University, Chongqing, China
}

Toll-like receptor 3 (TLR3) is an important member of the TLR family, which is an important group of pathogen-associated molecular patterns. TLR3 can recognize double-stranded RNA and induce activation of NF- $\mathrm{kB}$ and the production of type I interferons. In addition to its immune-associated role, TLR3 has also been detected in some tumors. However TLR3 can play protumor or antitumor roles in different tumors or cell lines. Here, we review the basic signaling associated with TLR3 and the pro- or antitumor roles of TLR3 in different types of tumors and discuss the possible reasons for the opposing roles of TLR3 in tumors.

\section{OPEN ACCESS}

Edited by:

Vincenzo Desiderio,

Second University of Naples, Italy

Reviewed by: Pietro Paolo Vitiello,

University of Turin, Italy Naomi Yamashita,

Musashino University, Japan

*Correspondence:

Hui Yang yanghui64@hotmail.com

Song Li

dlisong3@163.com

Xin Zheng

zhengxin08@tmmu.edu.cn

Specialty section:

This article was submitted to

Cancer Immunity and

Immunotherapy,

a section of the journal

Frontiers in Immunology

Received: 13 February 2021

Accepted: 06 April 2021

Published: 27 April 2021

Citation:

Zheng X, Li S and Yang H (2021)

Roles of Toll-Like Receptor 3

in Human Tumors.

Front. Immunol. 12:667454. doi: 10.3389/fimmu.2021.667454
Keywords: Toll-like receptor 3 - TLR-3, tumors, opposing role, dsRNA, pathogen-associated molecular pattern

\section{INTRODUCTION}

The link between cancer and inflammation has been firmly established by epidemiological investigations and in vivo and in vitro studies (1). Nearly $25 \%$ of cancers are attributable to chronic inflammation triggered by infection or physicochemical agents (2). Pattern recognition receptors (PRRs) can detect nonself or altered molecular patterns that act as important upstream regulators to control inflammation. Toll-like receptors (TLRs) are the best characterized PRRs that detect pathogen-associated molecular patterns (PAMPs) (3). Activation of TLRs triggers multiple proinflammatory and other signaling cascades to eliminate pathogens. However, if pathogens cannot be eliminated, they may elicit chronic inflammation though TLR signaling (4). In addition to PAMPs, TLRs recognize damage-associated molecular patterns (DAMPs), which are proteins or nucleic acids released during necrosis. Cell death results in the release of numerous DAMPs, such as heat-shock proteins (HSPs), fibrinogen, and endogenous double-stranded (ds) and single-stranded RNA. Once these molecules and substances are released from necrotic cells, they can activate TLRs expressed on other cells, which subsequently upregulate NF- $\mathrm{\kappa B}$ expression and release cytokines and chemokines (5).

The TLR family is composed of 10 members (TLR1-TLR10) in humans (6). TLRs are characterized by extracellular leucine-rich repeat (LRR) domains that recognize pathogens, a transmembrane domain for cellular localization and an intracellular Toll/IL-1 receptor (TIR) domain for the transduction of downstream signals (7). Different TLR members have specific subcellular localizations and agonists. TLR $1,-2,-4,-5,-6$, and -10 are cell surface proteins. TLR3 and TLR7-9 are located inside the cell in endocytic compartments and the endoplasmic reticulum. Surface TLR members respond to various bacterial lipoproteins, glycolipids, lipopolysaccharides and flagella. The intracellular proteins recognize oligonucleotides from self and microbial origins [for more details on TLR ligands, see review (8) and (9)]. 
Like other TLRs, TLR3 is predominantly expressed in innate immune cells such as macrophages, dendritic cells (DCs) and natural killer (NK) cells and are thus involved in the activation of innate immunity, which results in the production of proinflammatory cytokines, chemokines, and adhesion molecules (10). Intriguingly, increasing evidence has demonstrated that TLR3 is also expressed in tumor cells. The activation of TLR3 in both tumor cells and the tumor microenvironment, such as in typical innate immune cells, might play an opposing role in tumor progression.

In this review, we focus on the "double-edged sword" roles of TLR3 in tumor initiation and progression. We summarize the mechanism and clinical trials associated with the role of TLR3 in tumor behavior. In addition, we discuss the possible reasons for the dual roles of TLR3 in tumors.

\section{BASIC STRUCTURE AND CLASSIC SIGNALING PATHWAYS OF TLR3}

TLR3 is normally located in endosomes, where its luminal ectodomain (ECD) encounters its ligands, most important of which is dsRNA. The TLR3-ECD is composed of 23 LRRs and resembles a long solenoid bent into the shape of a horseshoe (11). The TLR3-ECD horseshoe is flat and highly glycosylated. The flatness of the TLR3 horseshoe facilitates ligand binding and signaling (12). The binding site of TLR3 is specific for dsRNA but does not distinguish between base sequences of dsRNA ligands. TLR3-ECDs interact with dsRNA at two sites on the glycan-free lateral surface. These sites interact only with the ribosephosphate backbone of the dsRNA, which leads to nonspecific base sequence binding of the TLR3 ligand (13). The minimum length required for dsRNA binding to TLR3 is $40-45 \mathrm{bp}$, and the optimal $\mathrm{pH}$ for dsRNA binding to TLR3-ECD is below 6.5 (13, 14). The affinity of TLR3 for dsRNA is high ( $10 \mathrm{nM})$ under optimal conditions but decreases as the $\mathrm{pH}$ increases above 6 and the dsRNA length decreases below 45 bp (13).

Once dsRNA binds to the TLR3-ECD, the adaptor protein TIR domain-containing adapter inducing interferon-b (TRIF or TICAM1) is recruited via a TIR-TIR domain interaction. Then, downstream signaling molecules access their binding sites upon colocalization of TRIF and TLR3 $(15,16)$. TRIF recruits downstream signaling molecules such as NAK-associated protein 1 (NAP1), tumor necrosis factor receptor-associated factor 3 (TRAF3), IRF-3-activating kinases, TANK-binding kinase 1 (TBK1) and IKB kinase (IKK-cc), which bind to the $\mathrm{N}$-terminal region of TRIF. This results in activation, phosphorylation and dimerization of IRF3 and IRF7, which induce the secretion of type I IFNs (17).

TLR3 can also activate NF- $\kappa$ B in a TRIF-dependent manner via receptor interacting protein 1 (RIP1) (18). Upon activation of TLR3, RIP1 is recruited to TRIF, where it is phosphorylated and polyubiquitinated by Peli1, an E3 ubiquitin ligase, which leads to the formation of a complex involving TRAF6, the TAK1-binding protein $\mathrm{TAB} 2$, the ubiquitin-activated MAP3K, TAK1 and the dsRNA-dependent kinase $\operatorname{PKR}(19,20)$. This complex then translocates to the cytoplasm. Then, TAK1 is phosphorylated and activated, which results in formation of the IKK complex, which is composed of IKKa, IKKb, NEMO and NF- KB $(19,21$, 22). Activation of NF- $\kappa B$ induces the expression of genes that maintain cell proliferation, promote invasion, and activate inflammatory cytokines. TAK1 can also activate MAP kinase signaling pathways by phosphorylating MKK6 (19). TRIF can recruit RIP3 and RIP1. The RIP1-RIP3 complex can play synergistic roles in cell survival. RIP1 can recruit FADD and induce caspase 8-mediated apoptosis. At the same time, RIP3 blocks RIP1-induced NF- $\mathrm{BB}$-mediated cell survival (23). RIP1 and RIP3 can both participate in the generation of reactive oxygen species (ROS), which induce cell apoptosis and necrosis $(24,25)$.

\section{ROLES OF TLR3 IN HUMAN CANCERS}

TLR3 is expressed in certain types of cancers (Table 1) that are often related to viral infection. TLR3 is closely related to clinical characteristics, prognosis and the probability of metastasis. However, the conclusions from in vitro or mouse model studies vary greatly.

\section{Cervical Cancer}

High-risk human papillomavirus (HPV) types that are related to the development of epithelial abnormalities of the cervix were identified as a necessary cause of cervical cancer (57). TLR3 is related to the clearance of HPV in healthy populations (58). HPV has also been demonstrated to modulate TLR expression and signaling, thus leading to persistent viral infection and carcinogenesis (59). DeCarlo et al. compared the expression of TLR3 among normal, premalignant and malignant cervical tissues and found that TLR3 expression was increased in dysplastic but not carcinomatous epithelium and that TLR3 mRNA levels were not changed in the carcinomatous stroma. This finding indicates that TLR3 is involved in early cervical carcinogenesis (26). In an in vitro study using the cervical cancer cell line U14, treatment with TLR3-siRNA significantly decreased cell growth, migration and invasion. This finding indicates the role of TLR3 in the development of cervical cancer (27). Polyinosinic-polycytidylic acid [i.e. poly(I:C)] is a synthetic analog of double-stranded RNA (dsRNA). Upon binding to its receptors, poly(I:C) is able to selectively activate numerous signaling pathways depending on the conditions. Poly (I:C) can be recognized by endosomal TLR3, thus usually considered as the agonist of TLR3. However, in the HeLa cell line, the TLR3 ligand poly (I:C) can induce apoptosis though IFN- $\beta$ production (28). Poly (I:C) can be an important adjuvant that enhances tumor killing. In a cervical cancer mouse model, poly (I:C) treatment after administration of the HPV E6/E7 oncogene-specific vaccine IVAG increased vaccine-specific IFN$\gamma$-secreting CD8 T cells by 5-fold (29). Pretreatment with E7(4462 ) and poly (I:C) can increase TNF- $\alpha$ and IFN- $\gamma$ secretion in NK92 cells and stimulate human DCs to secrete CD11c and CD86, which ultimately increases cytotoxicity against HeLa cells (60). 
TABLE 1 | TLR3 expressions in human cancers.

\begin{tabular}{|c|c|c|c|}
\hline Cancer Type & Tissue or Cell lines & TLR3 roles on cancer & Ref \\
\hline \multirow[t]{4}{*}{ Cervical cancer } & human cancer tissues & early carcinogenesis & (26) \\
\hline & U14 cell line & protumor & $(27)$ \\
\hline & Hela cell line & antitumor & (28) \\
\hline & mouse model & immune adjuvants & (29) \\
\hline \multirow[t]{7}{*}{ Hepatocellular carcinoma } & human cancer tissues & expressed more in large tumors & $(30)$ \\
\hline & human cancer tissues & antitumor & (31) \\
\hline & HepG2.2.15 cell line & antitumor & $(32)$ \\
\hline & MHCC97H cell line & antitumor & (33) \\
\hline & SMMC-7721 cell line & antitumor & $(33,34)$ \\
\hline & HUVEC cell line & antitumor & (33) \\
\hline & mouse model & antitumor & (35) \\
\hline \multirow[t]{4}{*}{ Multiple myeloma } & KMM1 cell line & protumor & (36) \\
\hline & $\mathrm{NCl}-\mathrm{H} 929$ cell line & antitumor & (36) \\
\hline & RPMI8226 cell line & antitumor & (36) \\
\hline & B16 implantation model & antitumor & (37) \\
\hline \multirow[t]{2}{*}{ Melanoma } & B16F10 mouse model & antitumor & (38) \\
\hline & C57BL/6 mouse model & antitumor & (39) \\
\hline \multirow[t]{10}{*}{ Breast cancer } & human cancer tissues & related to recurrence and metastasis & $(40)$ \\
\hline & Cama-1 cell line & antitumor & (41) \\
\hline & BT-483 cell line & antitumor & (41) \\
\hline & SW527 cell line & antitumor & $(41)$ \\
\hline & MCF-7 cell line & surface stimulation of TLR3: protumor & (42) \\
\hline & MCF-7 cell line & cytoplasmic stimulation of TLR3: antitumor & (42) \\
\hline & MDA-MB-231 cell line & surface stimulation of TLR3: protumor & (42) \\
\hline & MDA-MB-231 cell line & cytoplasmic stimulation of TLR3: antitumor & $(42)$ \\
\hline & MDA-MB-231 cell line & antimetastatic effect & (43) \\
\hline & MDA-MB-231 cell line & antitumor & (44) \\
\hline \multirow[t]{4}{*}{ Prostate cancer } & human cancer tissues & related to recurrence & $(45,46)$ \\
\hline & LNCaP cell line & antitumor & $(47,48)$ \\
\hline & PC3 cell line & antitumor & (49) \\
\hline & DU145 cell line & antitumor & (49) \\
\hline \multirow[t]{16}{*}{ Head and neck cancers } & human cancer tissues & related to poorly differentiated tumors & (50) \\
\hline & $\mathrm{PCl} 1$ cell line & protumor & (50) \\
\hline & BHY cell line & protumor & $(50)$ \\
\hline & Detroit-562 cell line & protumor & (51) \\
\hline & OC2 cell line & protumor & $(52,53)$ \\
\hline & HEp2 cell line & antitumor & (54) \\
\hline & SCC25 cell line & antitumor & $(54)$ \\
\hline & HSC2、3、 4 cell line & antitumor & $(54)$ \\
\hline & SAS & antitumor & $(54)$ \\
\hline & HSQ89 & antitumor & (54) \\
\hline & $\mathrm{HO}-1-\mathrm{u}-1$ & antitumor & $(54)$ \\
\hline & $\mathrm{HB}$ & antitumor & (55) \\
\hline & CAL27 & antitumor & (55) \\
\hline & WSU-HN6 & antitumor & (55) \\
\hline & YD-10B & antitumor & $(56)$ \\
\hline & YD-8 & antitumor & (56) \\
\hline
\end{tabular}

\section{Hepatocellular Carcinoma}

The leading causes of hepatocellular carcinoma (HCC) are chronic infections with hepatitis B (HBV) and hepatitis C viruses (HCV) worldwide (61). In HCC tissues, the positive detection rate of TLR3 varies from $52.7 \%$ to $91 \%$, and TLR3 is expressed in both the membrane and cytoplasm. Surface stimulation of TLR3 did not affect cell viability even when NF$\kappa \mathrm{B}$ was activated. However, cytoplasmic stimulation can induce apoptosis by downregulating the expression of antiapoptotic proteins $(62,63)$. Eiro et al. found that TLR3 levels were significantly higher in large tumors than in small tumors (30). However, TLR3 expression both in tumor cells and intratumoral cells correlates with prolonged survival (64-66). TLR3 was expressed at lower levels in HCC tissues than in adjacent tissues. Survivin, Bcl-2 and MMP2 expression were negatively correlated with TLR3 expression, but caspase $3,-8$, and -9 were positively correlated with TLR3 signaling proteins in human HCC tissues (31).

In an in vitro study, the TLR3 tended to have antitumor roles in different HCC cell lines. HBV secretion by the HepG2.2.15 cell line can be inhibited by dsRNA-mediated activation of TLR3 (67). In addition, the TLR3 agonist BM-06 can inhibit proliferation and invasion and simultaneously promote apoptosis of HepG2.2.15 cells by activating NF- $\kappa \mathrm{B}$ (32). The downstream factors Caspase 8, Bcl-2, and PCNA were all affected (68). Guo et al. found that the TLR3 agonists BM-06 and poly (I:C) 
can trigger apoptosis in MHCC97H, SMMC-7721 and HUVEC cell lines and inhibit cell migration (33). As TLR3 can both activate NF- $\kappa \mathrm{B}$ and IRF3, Khvalevsky et al. observed short-term IRF3 activation and a low level of IFN- $\beta$ in the Huh7 HCC cell line after TLR3 activation. In the HepG2 cell line, no induction of proinflammatory factors was observed, but apoptosis was induced via TLR3 activation (35). In the SMMC-7721 cell line, the combination of poly (I:C) and ATO can inhibit cell growth by increasing ROS generation and inducing mitochondrial dysfunction, in addition to upregulating caspase 3/8/9 and Bax and downregulating Bcl-2, survivin and Bid (34). In an HCC mouse model, poly (I:C)-induced TLR3 signaling can lead to a reduction in tumor enlargement and decrease tumor growth and cell proliferation $(69,70)$. In addition, in a spontaneous liver tumor mouse model, poly (I:C) treatment can increase remodeling of the tumor microenvironment, including intratumoral chemokine expression, NK cell activation and infiltration and proliferation of tumor-infiltrating T cells (64).

\section{Multiple Myeloma}

Many studies have investigated the roles of TLR3 in multiple myeloma (MM). There are many established myeloma cell lines. Jego et al. found that TLR3 was expressed in 5 of 16 investigated cell lines (NCI-H929, SBN, XG1, RPMI8226, and KMS11) (71). In addition, Abdi et al. found that the Fravel, L363, UM6, UM9, OPM1, OPM2 and U266 cell lines also expressed TLR3 (72). Among these TLR3-expressing myeloma cell lines, the effects of poly (I:C) stimulation are not consistent. A study by Chiron et al. showed that even though XG1 and OPM2 cells express TLR3, they did not respond to poly (I:C). Poly (I:C)-mediated activation of NF- $\mathrm{KB}$ was observed in NCI-H929, RPMI8226 and KMM1 cells, which express TLR3. After stimulation, the proliferation of KMM1 cells was increased, but the proliferation of NCI-H929 and RPMI8226 cells was decreased. Apoptosis of the latter two cell lines was due to activation of the IFN- $\alpha$-p38-MAPK pathway and ERK1/2 pathway, which are involved in cell death (36). Apoptosis in myeloma can also be induced through the TLR3/ TRIF/caspase- 8 pathway (73), TLR3/IFN- $\beta$ pathway (74) and TLR3/IFN- $\alpha / \mathrm{Bcl}-2$ pathway and caspase-3, caspase-9, X-IAP, cFLIP, and A20 (75). Immune cells can efficiently affect myeloma cells via stimulation with TLR3 agonists. In a B16 tumor implantation model, poly (I:C) can activate $\mathrm{mDC}$-derived antitumor NK cells, which led to the retardation of tumor growth (37).

\section{Melanoma}

TLR3 is highly expressed on human melanoma cells, and TLR3 activation can induce activation of downstream NF- $\kappa B$ and cell migration (76). In a poorly immunogenic B16-OVA melanoma tumor model, poly (I:C) was used an adjuvant that combined with anti-CD40 and efficiently induced tumor rejection (77). These antitumoral effects must occur in combination with the induced immunochemotherapeutic regimen of vaccination against tumor antigens (78). In the B16F10 mouse model, poly (I:C) liposomes can inhibit melanoma growth in a dosedependent manner, accompanied by increasing numbers of
TRP-2-tetramer(+)CD8(+) cells in lymph nodes, maturation of DCs and increasing numbers of TRP1-specific IFN- $\gamma$-producing cells in lymph nodes and the spleen (38). Poly (I:C) can also inhibit the metastasis of myeloma cells. In a B16 melanoma cell C57BL/6 mouse model, intraperitoneal injection of poly (I:C) can inhibit lung and liver metastasis of B16 cells in a manner dependent on NK cells and IFN- $\gamma$, along with increasing the number of IFN-producing killer DCs in the spleen, lung and liver (39).

\section{Breast Cancer}

IFN $-\gamma$ is considered a key factor associated with the immune dysfunction that is common in breast cancer. Amarante et al. found that among patients with high expression of IFN- $\gamma$, TLR3 mRNA expression was significantly higher in breast cancer tissues than in healthy tissues, while TLR3 protein expression did not differ between healthy and breast cancer tissues (79). In contrast, Gonzalez et al. found that the expression level of TLR3 was related to recurrence and an increased probability of metastasis (40). In a randomized clinical trial, adjuvant treatment with poly(A:U) dsRNA was associated with a significant decrease in the risk of metastatic relapse in TLR3(+) breast cancer patients but not in TLR3(-) patients (80).

In an in vitro study, activation of TLR3 by dsRNA can trigger apoptosis in human breast cancer cells, which involves Toll/IL$1 \mathrm{R}$ domain-containing adaptors that induce IFN- $\beta$ and type I IFN autocrine signaling, as well as activation of extrinsic caspases (41). Interestingly, a study by Bondhopadhyay et al. used MCF-7 and MDA-MB-231 breast cancer cell lines and found that surface stimulation of TLR3 can increase cellular survivability, growth, E-cadherin expression and thus metastasis. However, cytoplasmic stimulation led to a decrease in cell survival (42). Another TLR3 agonist, poly (A:U), did not have cytotoxic or apoptotic effects on the MDA-MB-231 cell line but decreased the expression of MMP2 at high concentrations, which indicated an antimetastatic effect (43). Galli et al. found that after treatment with poly (I:C), microRNA (miR)29b, miR29c, miR148b, and miR152 were increased in MDA-MB-231 cells. These microRNAs led to demethylation and re-expression of the oncosuppressor RAR $\beta$, thus inducing apoptosis (44). TLR3 stimulation can also result in the induction of breast cancer stem cells (CSCs). TLR3 stimulation can trigger coactivation of $\mathrm{NF}-\kappa \mathrm{B}$ and $\beta$-catenin, which promote breast cancer cells to acquire a CSC phenotype in vivo and in vitro (81).

\section{Prostate Cancer}

Prostate cancer tissues exhibited higher expression levels of TLR3 than healthy tissues, which was also related to a higher probability of biochemical recurrence (45). Schulz et al. also found that the expression of TLR3 was associated with prostate cancer recurrence (46). In vitro, the prostate cancer cell lines LNCaP and DU-145 can respond to TLR3 agonists through NF$\kappa \mathrm{B}$ activation, but the more aggressive PC3 cell line cannot. After activation of TLR3, LNCaP and DU-145 cells upregulated inflammatory molecules and cytokines that attracted immune effectors (47). In the LNCaP cell line, poly (I:C) induced intrinsic and extrinsic apoptotic pathways through interferon regulatory 
factor-3 signaling (48), and the PI3K/Akt pathway was inactivated, accompanied by the participation of the autophagy-, proliferation- and apoptosis-related proteins cyclin D1, c-Myc, p53 and NOXA (82). Mitogen-activated protein kinases were activated by poly (I:C) in both LNCap and PC3 cells. In addition, the interferon-independent pathway p38 and c-jun $\mathrm{N}$-terminal kinase/protein kinase $\mathrm{C} \alpha$ were also activated in the LNCaP cell line (83). Surprisingly, in PC3 cells, activation of TLR3 can increase the expression of the specific I.3 isoform of HIF- $1 \alpha$, which results in reduced apoptosis and VEGF secretion; that is, TLR3 plays an antitumor role. In the LNCaP cell line, activation of TLR3 cannot induce nuclear accumulation of HIF-2 $\alpha$ (49). A study by Palchetti et al. focused on the role of the TLR3/Scr/STAT1 axis in apoptosis in PC3 and DU145 cell lines (84).

\section{Head and Neck Cancers}

Head and neck cancers also express TLR3. Approximately 73.2\% of oral squamous cell carcinoma (OSCC) tissues express TLR3, and TLR3 expression is correlated with poorly differentiated tumors. TLR3 can activate NF- $\mathrm{KB} / \mathrm{c}-\mathrm{Myc}$ and increase the proliferation of head and neck squamous cell carcinoma (HNSCC) cells. TLR3 was considered to contribute to the malignant phenotype that leads to invasion (50). In the HNSCC cell line Detroit-562, activation of TLR3/NF- $\kappa B$ can upregulate the expression of ICAM-1, IL-6, IL-8, and IL-1 $\beta$ and promote cell migration but decrease cell viability (51). TLR3 activation can induce metabolic reprogramming and lead to increased aerobic glycolysis and cell migration though changes in the expression of pyruvate kinase, CD44 variants and MMP9 in Detroit 562 cell line (52). Stimulation of the TLR3-expressing OC2 cell line (a head and neck cancer cell line) with poly (I:C) can induce the phosphorylation of IRF3 and I $\mathrm{KB}$, ultimately increasing the secretion of IL- 6 and CCL5. CCL5 can promote the migration of OC2 cells (53). TLR3 may contribute to tumor development and lead to cisplatin resistance in OC2 cells (54). However, in 8 other head and neck cancer cell lines (HEp2, SCC25, HSC2, HSC3, HSC4, SAS, HSQ89 and HO-1-u-1), poly (I:C)-stimulated TLR3 induced apoptosis in these cell lines though downregulating survivin expression (55). In addition, in the OSCC cell lines HB, CAL27 and WSU-HN6, poly (I:C) induced apoptosis via TLR3 though the production of IFN- $\beta$ and activation of caspase 3 and 9 (56). In the OSCC cell lines YD-10B and YD-8, apoptosis was induced via a mitochondria-dependent pathway (85).

\section{Other Tumors}

In colorectal cancer, TLR3 is considered a marker of colon tissue metaplasia. The normal colonic mucosa expresses the highest levels of TLR3. As the malignancy stage increases from polyp to stage I to III adenocarcinoma, the expression of TLR3 decreases $(86,87)$. In vitro, poly (I:C) can induce necroptosis in the colon cancer cell line CT26 though the TLR3-TICAM-1-RIP3 axis to produce reactive oxygen (88). In mouse colon tumor models, the combination of poly (I:C) and vaccination with the CEA epitope can cause increase the number of mature DCs and induce elevated expression IL-12 and proliferation of lymphocytes (89). TLR3 is highly expressed in human gastric cancer tissues and is correlated with worse clinical characteristics such as poor overall survival, lymph node invasion and poor prognosis (90). However, in neuroblastomas, positive TLR3 expression is associated with favorable histology and prognosis (91). In normal renal tissues, TLR3 expression is limited. In clear cell renal cell carcinoma (CCRCC), TLR3 is highly expressed and correlated with lung metastasis (92). TLR3 is also highly expressed in nonsmall cell lung cancer and esophageal squamous cells compared with that of healthy tissues $(93,94)$. Activation of lung alveolar epithelial TLR3 by tumor exosomal RNAs can recruit neutrophils, which can promote the formation of the lung premetastatic niche (95). However, activation of TLR3 in the Lewis lung cancer cell line 3LL induces M1 polarization of tumor-associated macrophages and can inhibit tumor growth (96). The inhibitory role of TLR3 has been are verified in LL/2 and A549 NSCLC cells (97). The expression of TLR3 can be considered a biomarker for lymph node metastasis and increased depth of invasion of esophageal squamous cell carcinoma (94). In pituitary adenomas (PAs), TLR3 is expressed in every PA sample and correlated with the invasion and proliferation of PAs. In an in vitro study, activation of TLR3 in the rat pituitary adenoma GH3 cell line induced proliferation, invasion and secretion of inflammatory cytokines (98).

\section{CLINICAL APPLICATIONS OF TLR3- BASED IMMUNE ADJUVANTS}

Tumor vaccines are used to treat and protect against tumors. The innate immune response is important in supporting the development of adaptive immunity and thus can be used to accelerate and enhance induction of vaccine-specific responses (99). Stimulation with poly (I:C) can result in strong type I and III interferon and Th1 cytokine responses. Type I interferon production is considered to be critical for efficacy of poly (I:C) as a Th1-inducing adjuvant (100), which can impact APC maturation, antigen processing and the responding antigenspecific B and T cells $(101,102)$. As high doses of poly (I:C) have been shown to cause shock, renal failure and coagulopathies in Phase I-II clinical trials of cancer patients (103), two safer derivatives of poly (I:C) were produced, poly-ICLC (Hiltonol ${ }^{\circledR}$ ) and poly- $\mathrm{IC}_{12} \mathrm{U}$ (Ampligen ${ }^{\circledR}$ ).

Poly- $\mathrm{IC}_{12} \mathrm{U}$ has been shown to induce functional, mature $\mathrm{DCs}$ in cancer patients (104). In Phase I and Phase II clinical trials for leukemia and neuroblastoma cancer patients, poly-ICLC elicited strong interferon responses and was partially successful in inducing tumor regression $(105,106)$. In addition, poly-ICLC also enhanced antibody titers and CD4 and CD8 T cell responses in an ovarian cancer clinical trial (107). Poly- $\mathrm{IC}_{12} \mathrm{U}$ was well tolerated in long-term Phase I-II clinical trials involving cancer patients (108). High-dose poly-ICLC therapy was associated with hypotension, fever and anemia. However, once the dose and frequency of delivery were optimized, the treatment was be well tolerated in patients $(106,109,110)$. A defined TLR3-specific adjuvant, which is a chimeric molecule consisting of 
phosphorothioate ODN-guided dsRNA, was synthesized that can't activate the RIG-1/MDA5 pathway. It elicited far less cytokine production than poly(I:C) in vitro and in vivo (111).

\section{TLR3 DIVERSITY IN DIFFERENT TUMORS}

The expression of TLR3 in cancer cells seems to be quite common, but the roles and molecular mechanism of TLR3 in cancers are quite complicated. The downstream factors NF- $\kappa B$ and IRF3 are two important transcription factors associated with TLR3 signaling (6). Activation of NF- $\mathrm{KB}$ can induce inflammatory cytokine and MMP secretion, which may promote cancer progression (112). However, activation of IRF3 can induce the production of type I interferon, which can result in cancer cell apoptosis (17). These two different pathways may be the basis of the different outcomes of TLR3 activation in cancer cells. Overall, TLR3 tends to play an antitumor role, but its protumor role should be mentioned in clinical applications.

TLR3 is normally located in endosomes. Cell surface TLR3 expression has been detected in fibroblasts, vascular endothelial cells and epithelial cells (113). In some immune cells, cell surface expression of TLR3 has also been detected. TLR3 is not expressed on the cell surface of human monocyte-derived DCs (114), but an established mAb against mouse TLR3 was used to show that TLR3 was highly expressed on the cell surface of splenic CD8 ${ }^{+}$ DCs and marginal zone B cells. TLR3 is also expressed on the surface of macrophages, and even though its expression is weak, it can enhance TLR3 responses to dsRNA (115). Activation of cell surface TLR3 leads to a proinflammatory response, whereas TLR3 activation in endosomal compartments by dsRNA is characterized by type I interferon production and plays an anti-inflammatory role (113). In different types of tumors, the

\section{REFERENCES}

1. Balkwill F, Mantovani A. Inflammation and Cancer: Back to Virchow? Lancet (2001) 357:539-45. doi: 10.1016/S0140-6736(00)04046-0

2. Korniluk A. From Inflammation to Cancer. Ir J Med Sci (2017) 186:57-62. doi: 10.1007/s11845-016-1464-0

3. Takeuchi O, Akira S. Pattern Recognition Receptors and Inflammation. Cell (2010) 140:805-20. doi: 10.1016/j.cell.2010.01.022

4. Rakoff-Nahoum S, Medzhitov R. Toll-Like Receptors and Cancer. Nat Rev Cancer (2009) 9:57-63. doi: 10.1038/nrc2541

5. Sato Y, Goto Y, Narita N, Hoon DSB. Cancer Cells Expressing Toll-like Receptors and the Tumor Microenvironment. Cancer Microenviron (2009) 2:205-14. doi: 10.1007/s12307-009-0022-y

6. Kawasaki T, Kawai T. Toll-Like Receptor Signaling Pathways. Front Immunol (2014) 5:461. doi: 10.3389/fimmu.2014.00461

7. Akira S, Takeda K. Toll-Like Receptor Signalling. Nat Rev Immunol (2004) 4:499-511. doi: 10.1038/nri1391

8. Tsan M-F. Endogenous Ligands of Toll-like Receptors. J Leukoc Biol (2004) 76:514-9. doi: 10.1189/jlb.0304127

9. Hussein WM, Liu TY, Skwarczynski M, Toth I. Toll-Like Receptor Agonists: A Patent Review (2011-2013). Expert Opin Ther Pat (2014) 24:453-70. doi: $10.1517 / 13543776.2014 .880691$

10. Iwasaki A, Medzhitov R. Toll-Like Receptor Control of the Adaptive Immune Responses. Nat Immunol (2004) 5:987-95. doi: 10.1038/ni1112

11. Bell JK, Mullen GED, Leifer CA, Mazzoni A, Davies DR, Segal DM. Leucine-Rich Repeats and Pathogen Recognition in Toll-like Receptors. expression of TLR3 varies greatly. There is not enough information on cell surface expression of TLR3 in different tumors. This may be the reason why in different cancers, the effects of TLR3 can be varied. In addition, in the same kind of cancer, the role of TLR3 also differs in diverse cell lines, as we previously mentioned.

\section{CONCLUSION}

In further studies on TLR3, the role of cell surface TLR3 should not be ignored. Cell surface TLR3 expression should be measured and localized by immunohistochemistry or other methods. The downstream signaling of TLR3 should be comprehensively considered, both the NF- $\kappa \mathrm{B}$ pathway and the IRF3/7 pathway. In related TLR3 clinical trials, the dual role of TLR3 should be considered, and activation of TLR3 may increase the progression of some kinds of tumors or in some individuals. Further mechanistic investigations on the dual roles of TLR3 in tumor biology are needed.

\section{AUTHOR CONTRIBUTIONS}

All authors listed have made a substantial, direct, and intellectual contribution to the work and approved it for publication.

\section{FUNDING}

This work was supported by National Natural Science Foundation of China (No. 81801369).

Trends Immunol (2003) 24:528-33. doi: 10.1016/S1471-4906(03) 00242-4

12. Kobe B, Deisenhofer J. The Leucine-Rich Repeat: A Versatile Binding Motif. Trends Biochem Sci (1994) 19:415-21. doi: 10.1016/0968-0004(94)90090-6

13. Leonard JN, Ghirlando R, Askins J, Bell JK, Margulies DH, Davies DR, et al. The TLR3 Signaling Complex Forms by Cooperative Receptor Dimerization. Proc Natl Acad Sci USA (2008) 105:258-63. doi: 10.1073/pnas.0710779105

14. de Bouteiller O, Merck E, Hasan UA, Hubac S, Benguigui B, Trinchieri G, et al. Recognition of Double-Stranded RNA by Human Toll-Like Receptor 3 and Downstream Receptor Signaling Requires Multimerization and an Acidic Ph. J Biol Chem (2005) 280:38133-45. doi: 10.1074/jbc.M507163200

15. Oshiumi H, Matsumoto M, Funami K, Akazawa T, Seya T. Ticam-1, an Adaptor Molecule That Participates in Toll-like Receptor 3-Mediated Interferon-Beta Induction. Nat Immunol (2003) 4:161-7. doi: 10.1038/ni886

16. Tatematsu M, Ishii A, Oshiumi H, Horiuchi M, Inagaki F, Seya T, et al. A Molecular Mechanism for Toll-IL-1 Receptor Domain-containing Adaptor Molecule-1-mediated Irf-3 Activation. J Biol Chem (2010) 285:20128-36. doi: 10.1074/jbc.M109.099101

17. Honda K, Takaoka A, Taniguchi T. Type I Interferon Gene Induction by the Interferon Regulatory Factor Family of Transcription Factors. Immunity (2006) 25:349-60. doi: 10.1016/j.immuni.2006.08.009

18. Meylan E, Burns K, Hofmann K, Blancheteau V, Martinon F, Kelliher M, et al. RIP1 is an Essential Mediator of Toll-like Receptor 3-Induced NFKappa B Activation. Nat Immunol (2004) 5:503-7. doi: 10.1038/ni1061

19. Jiang Z, Zamanian-Daryoush M, Nie H, Silva AM, Williams BRG, Li X. Poly (I-C)-Induced Toll-like Receptor 3 (TLR3)-Mediated Activation of Nfkappa 
$B$ and MAP Kinase is Through an Interleukin-1 Receptor-Associated Kinase (IRAK)-Independent Pathway Employing the Signaling Components TLR3TRAF6-TAK1-TAB2-PKR. J Biol Chem (2003) 278:16713-9. doi: 10.1074/ jbc.M300562200

20. Chang M, Jin W, Sun S-C. Peli1 Facilitates TRIF-dependent Toll-Like Receptor Signaling and Proinflammatory Cytokine Production. Nat Immunol (2009) 10:1089-95. doi: 10.1038/ni.1777

21. Shim J-H, Xiao C, Paschal AE, Bailey ST, Rao P, Hayden MS, et al. TAK1, But Not TAB1 or TAB2, Plays an Essential Role in Multiple Signaling Pathways In Vivo. Genes Dev (2005) 19:2668-81. doi: 10.1101/gad.1360605

22. Cusson-Hermance N, Khurana S, Lee TH, Fitzgerald KA, Kelliher MA. Rip1 Mediates the Trif-Dependent Toll-like Receptor 3- and 4-Induced NF-??B Activation But Does Not Contribute to Interferon Regulatory Factor 3 Activation. J Biol Chem (2005) 280:36560-6. doi: 10.1074/jbc.M506831200

23. Kaiser WJ, Offermann MK. Apoptosis Induced by the Toll-Like Receptor Adaptor TRIF is Dependent on its Receptor Interacting Protein Homotypic Interaction Motif. J Immunol (2005) 174:4942-52. doi: 10.4049/ jimmunol.174.8.4942

24. Cho Y, Challa S, Moquin D, Genga R, Ray TD, Guildford M, et al. Phosphorylation-Driven Assembly of the RIP1-RIP3 Complex Regulates Programmed Necrosis and Virus-Induced Inflammation. Cell (2009) 137:1112-23. doi: 10.1016/j.cell.2009.05.037

25. Festjens N, Vanden Berghe T, Cornelis S, Vandenabeele P. RIP1, a Kinase on the Crossroads of a Cell's Decision to Live or Die. Cell Death Differ (2007) 14:400-10. doi: 10.1038/sj.cdd.4402085

26. Decarlo CA, Rosa B, Jackson R, Niccoli S, Escott NG, Zehbe I. Toll-Like Receptor Transcriptome in the HPV-positive Cervical Cancer Microenvironment. Clin Dev Immunol (2012) 2012:785825. doi: 10.1155/ 2012/785825

27. Liu HN, Shi HR, Zhao XL, Zhang RT, Liu GZ, Zhang JX. The TLR3, PI3K, Survivin, FasL, and Fas Genes as Major Risk Factors of Occurrence and Development of Cervical Cancer Disease. Gene (2014) 550:27-32. doi: 10.1016/j.gene.2014.08.009

28. Jiang Q, Wei H, Tian Z. Poly I:C Enhances Cycloheximide-Induced Apoptosis of Tumor Cells Through TLR3 Pathway. BMC Cancer (2008) 8:12. doi: 10.1186/1471-2407-8-12

29. Domingos-Pereira S, Decrausaz L, Derré L, Bobst M, Romero P, Schiller JT, et al. Intravaginal TLR Agonists Increase Local Vaccine-Specific CD8 T Cells and Human Papillomavirus-Associated Genital-Tumor Regression in Mice. Mucosal Immunol (2013) 6:393-404. doi: 10.1038/mi.2012.83

30. Eiró N, Altadill A, Juárez LM, Rodríguez M, González LO, Atienza S, et al. Toll-Like Receptors 3, 4 and 9 in Hepatocellular Carcinoma: Relationship With Clinicopathological Characteristics and Prognosis. Hepatol Res (2014) 44:769-78. doi: 10.1111/hepr.12180

31. Yuan M-M, Xu Y-Y, Chen L, Li X-Y, Qin J, Shen Y. TLR3 Expression Correlates With Apoptosis, Proliferation and Angiogenesis in Hepatocellular Carcinoma and Predicts Prognosis. BMC Cancer (2015) 15:245. doi: 10.1186/s12885-015-1262-5

32. Chen L, Xu Y-Y, Zhou J-M, Wu Y-Y, Qun E, Zhu Y-Y. Tlr3 dsRNA Agonist Inhibits Growth and Invasion of HepG2.2.15 HCC Cells. Oncol Rep (2012) 28:200-6. doi: 10.3892/or.2012.1791

33. Guo Z, Chen L, Zhu Y, Zhang Y, He S, Qin J, et al. Double-Stranded RNAinduced TLR3 Activation Inhibits Angiogenesis and Triggers Apoptosis of Human Hepatocellular Carcinoma Cells. Oncol Rep (2012) 27:396-402. doi: 10.3892/or.2011.1538

34. Shen P, Jiang T, Lu H, Han H, Luo R. Combination of Poly I:C and Arsenic Trioxide Triggers Apoptosis Synergistically Via Activation of TLR3 and Mitochondrial Pathways in Hepatocellular Carcinoma Cells. Cell Biol Int (2011) 35:803-10. doi: 10.1042/CBI20100739

35. Khvalevsky E, Rivkin L, Rachmilewitz J, Galun E, Giladi H. TLR3 Signaling in a Hepatoma Cell Line is Skewed Towards Apoptosis. J Cell Biochem (2007) 100:1301-12. doi: 10.1002/jcb.21119

36. Chiron D, Pellat-Deceunynck C, Amiot M, Bataille R, Jego G. TLR3 Ligand Induces NF-\{kappa\}B Activation and Various Fates of Multiple Myeloma Cells Depending on IFN-\{alpha\} Production. J Immunol (2009) 182:4471-8. doi: $10.4049 /$ jimmunol.0803113

37. Akazawa T, Ebihara T, Okuno M, Okuda Y, Shingai M, Tsujimura K, et al. Antitumor NK Activation Induced by the Toll-like Receptor 3-TICAM-1
(TRIF) Pathway in Myeloid Dendritic Cells. Proc Natl Acad Sci USA (2007) 104:252-7. doi: 10.1073/pnas.0605978104

38. Fujimura T, Nakagawa S, Ohtani T, Ito Y, Aiba S. Inhibitory Effect of the Polyinosinic-Polycytidylic Acid/Cationic Liposome on the Progression of Murine B16F10 Melanoma. Eur I Immunol (2006) 36:3371-80. doi: 10.1002/ eji.200636053

39. Jiang Q, Wei H, Tian Z. IFN-Producing Killer Dendritic Cells Contribute to the Inhibitory Effect of Poly I:C on the Progression of Murine Melanoma. J Immunother 31(6):555-62. doi: 10.1097/CJI.0b013e31817d8e75

40. González-Reyes S, Marín L, González L, González LO, del Casar JM, Lamelas ML, et al. Study of TLR3, TLR4 and TLR9 in Breast Carcinomas and Their Association With Metastasis. BMC Cancer (2010) 10:665. doi: 10.1186/14712407-10-665

41. Salaun B, Coste I, Rissoan M-C, Lebecque SJ, Renno T. TLR3 can Directly Trigger Apoptosis in Human Cancer Cells. J Immunol (2006) 176:4894-901. doi: 10.4049/jimmunol.176.8.4894

42. Bondhopadhyay B, Moirangthem A, Basu A. Innate Adjuvant Receptor Tolllike Receptor 3 can Promote Breast Cancer Through Cll Surface. Tumour Biol (2015) 36:1261-71. doi: 10.1007/s13277-014-2737-8

43. Alizadeh N, Amiri MM, Salek Moghadam A, Zarnani AH, Saadat F, Safavifar F, et al. Effect of Toll-Like Receptor 3 Agonists on the Functionality and Metastatic Properties of Breast Cancer Cell Model. Iran J Allergy Asthma Immunol (2013) 12:161-7.

44. Galli R, Paone A, Fabbri M, Zanesi N, Calore F, Cascione L, et al. Toll-Like Receptor 3 (TLR3) Activation Induces microRNA-dependent Reexpression of Functional Rar $\beta$ and Tumor Regression. Proc Natl Acad Sci USA (2013) 110:9812-7. doi: 10.1073/pnas.1304610110

45. González-Reyes S, Fernández JM, González LO, Aguirre A, Suárez A, González JM, et al. Study of TLR3, TLR4, and TLR9 in Prostate Carcinomas and Their Association With Biochemical Recurrence. Cancer Immunol Immunother (2011) 60:217-26. doi: 10.1007/s00262010-0931-0

46. Schulz WA, Alexa A, Jung V, Hader C, Hoffmann MJ, Yamanaka M, et al. Factor Interaction Analysis for Chromosome 8 and DNA Methylation Alterations Highlights Innate Immune Response Suppression and Cytoskeletal Changes in Prostate Cancer. Mol Cancer (2007) 6:14. doi: 10.1186/1476-4598-6-14

47. Galli R, Starace D, Busà R, Angelini DF, Paone A, De Cesaris P, et al. TLR Stimulation of Prostate Tumor Cells Induces Chemokine-Mediated Recruitment of Specific Immune Cell Types. J Immunol (2010) 184:665869. doi: 10.4049/jimmunol.0902401

48. Gambara G, Desideri M, Stoppacciaro A, Padula F, De Cesaris P, Starace D, et al. TLR3 Engagement Induces IRF-3-dependent Apoptosis in AndrogenSensitive Prostate Cancer Cells and Inhibits Tumour Growth In Vivo. J Cell Mol Med (2015) 19:327-39. doi: 10.1111/jcmm.12379

49. Paone A, Galli R, Gabellini C, Lukashev D, Starace D, Gorlach A, et al. TollLike Receptor 3 Regulates Angiogenesis and Apoptosis in Prostate Cancer Cell Lines Through Hypoxia-Inducible Factor 1 Alpha. Neoplasia (2010) 12:539-49. doi: 10.1593/neo.92106

50. Pries R, Hogrefe L, Xie L, Frenzel H, Brocks C, Ditz C, et al. Induction of cMyc-dependent Cell Proliferation Through Toll-Like Receptor 3 in Head and Neck Cancer. Int J Mol Med (2008) 21:209-15. doi: 10.3892/ ijmm.21.2.209

51. Rydberg C, Månsson A, Uddman R, Riesbeck K, Cardell L-O. Toll-Like Receptor Agonists Induce Inflammation and Cell Death in a Model of Head and Neck Squamous Cell Carcinomas. Immunology (2009) 128:e600-11. doi: $10.1111 /$ j.1365-2567.2008.03041.x

52. Matijevic Glavan T, Cipak Gasparovic A, Vérillaud B, Busson P, Pavelic J. Toll-Like Receptor 3 Stimulation Triggers Metabolic Reprogramming in Pharyngeal Cancer Cell Line Through Myc, MAPK, and HIF. Mol Carcinog (2017) 56:1214-26. doi: $10.1002 / \mathrm{mc} .22584$

53. Chuang H-C, Huang C-C, Chien C-Y, Chuang J-H. Toll-Like Receptor 3Mediated Tumor Invasion in Head and Neck Cancer. Oral Oncol (2012) 48:226-32. doi: 10.1016/j.oraloncology.2011.10.008

54. Chuang H-C, Chou M-H, Chien C-Y, Chuang J-H, Liu Y-L. Triggering TLR3 Pathway Promotes Tumor Growth and Cisplatin Resistance in Head and Neck Cancer Cells. Oral Oncol (2018) 86:141-9. doi: 10.1016/ j.oraloncology.2018.09.015 
55. Nomi N, Kodama S, Suzuki M. Toll-Like Receptor 3 Signaling Induces Apoptosis in Human Head and Neck Cancer Via Survivin Associated Pathway. Oncol Rep (2010) 24:225-31. doi: 10.3892/or_00000850

56. Luo Q, Hu S, Yan M, Sun Z, Chen W, Chen F. Activation of Toll-like Receptor 3 Induces Apoptosis of Oral Squamous Carcinoma Cells In Vitro and In Vivo. Int J Biochem Cell Biol (2012) 44:1266-75. doi: 10.1016/ j.biocel.2012.04.025

57. Woodman CBJ, Collins SI, Young LS. The Natural History of Cervical HPV Infection: Unresolved Issues. Nat Rev Cancer (2007) 7:11-22. doi: 10.1038/ nrc2050

58. Scott ME, Ma Y, Farhat S, Moscicki A-B. Expression of Nucleic Acid-Sensing Toll-like Receptors Predicts HPV16 Clearance Associated With an E6directed Cell-Mediated Response. Int J Cancer (2015) 136:2402-8. doi: $10.1002 / \mathrm{ijc} .29283$

59. Zhou Q, Zhu K, Cheng H. Toll-Like Receptors in Human Papillomavirus Infection. Arch Immunol Ther Exp (Warsz) (2013) 61:203-15. doi: 10.1007/ s00005-013-0220-7

60. Huang Y-K, Zheng Z, Cheng C-X, Wang L-Y, Li Y-R, Qiu F. The Antitumor Effect of the Toll-Like Receptor 3 Ligand Polyinosinic-Cytidylic Acid as an Adjuvant. Cancer Immunol Immunother (2013) 62:237-44. doi: 10.1007/ s00262-012-1328-z

61. Tornesello ML, Buonaguro L, Izzo F, Buonaguro FM. Molecular Alterations in Hepatocellular Carcinoma Associated With Hepatitis B and Hepatitis C Infections. Oncotarget (2016) 7(18):25087-102. doi: 10.18632/ oncotarget.7837

62. Yoneda K, Sugimoto K, Shiraki K, Tanaka J, Beppu T, Fuke H, et al. Dual Topology of Functional Toll-like Receptor 3 Expression in Human Hepatocellular Carcinoma: Differential Signaling Mechanisms of TLR3induced NF-Kappab Activation and Apoptosis. Int J Oncol (2008) 33:929-36. doi: 10.3892/ijo_00000080

63. Nojiri K, Sugimoto K, Shiraki K, Tameda M, Inagaki Y, Kusagawa S, et al. The Expression and Function of Toll-like Receptors 3 and 9 in Human Colon Carcinoma. Oncol Rep (2013) 29:1737-43. doi: 10.3892/or.2013.2322

64. Chew V, Tow C, Huang C, Bard-Chapeau E, Copeland NG, Jenkins NA, et al. Toll-Like Receptor 3 Expressing Tumor Parenchyma and Infiltrating Natural Killer Cells in Hepatocellular Carcinoma Patients. J Natl Cancer Inst (2012) 104:1796-807. doi: 10.1093/jnci/djs436

65. Chew V, Abastado J-P. Immunomodulation of the Tumor Microenvironment by Toll-like Receptor-3 (TLR3) Ligands. Oncoimmunology (2013) 2:e23493. doi: 10.4161/onci.23493

66. Bonnin M, Fares N, Testoni B, Estornes Y, Weber K, Vanbervliet B, et al. Toll-Like Receptor 3 Downregulation is an Escape Mechanism From Apoptosis During Hepatocarcinogenesis. J Hepatol (2019) 71:763-72. doi: 10.1016/j.jhep.2019.05.031

67. Chen X-L, Xu Y-Y, Chen L, Wang G-L, Shen Y. Tlr3 Plays Significant Roles Against HBV-Associated Hcc. Gastroenterol Res Pract (2015) 2015:572171. doi: $10.1155 / 2015 / 572171$

68. Xu Y-Y, Chen L, Wang G-L, Zhou J-M, Zhang Y-X, Wei Y-Z, et al. A Synthetic dsRNA, as a TLR3 Pathway Synergist, Combined With Sorafenib Suppresses HCC In Vitro and In Vivo. BMC Cancer (2013) 13:527. doi: 10.1186/1471-2407-13-527

69. Bergé M, Bonnin P, Sulpice E, Vilar J, Allanic D, Silvestre J-S, et al. Small Interfering RNAs Induce Target-Independent Inhibition of Tumor Growth and Vasculature Remodeling in a Mouse Model of Hepatocellular Carcinoma. Am J Pathol (2010) 177:3192-201. doi: 10.2353/ajpath. 2010.100157

70. Xu Y-Y, Chen L, Zhou J-M, Wu Y-Y, Zhu Y-Y. Inhibitory Effect of Dsrna TLR3 Agonist in a Rat Hepatocellular Carcinoma Model. Mol Med Rep (2013) 8:1037-42. doi: 10.3892/mmr.2013.1646

71. Jego G, Bataille R, Geffroy-Luseau A, Descamps G, Pellat-Deceunynck C. Pathogen-Associated Molecular Patterns are Growth and Survival Factors for Human Myeloma Cells Through Toll-like Receptors. Leukemia (2006) 20:1130-7. doi: 10.1038/sj.leu.2404226

72. Abdi J, Mutis T, Garssen J, Redegeld F. Characterization of the Toll-like Receptor Expression Profile in Human Multiple Myeloma Cells. PloS One (2013) 8:e60671. doi: 10.1371/journal.pone.0060671

73. Weber A, Kirejczyk Z, Besch R, Potthoff S, Leverkus M, Häcker G. Proapoptotic Signalling Through Toll-like Receptor-3 Involves TRIF- dependent Activation of Caspase-8 and is Under the Control of Inhibitor of Apoptosis Proteins in Melanoma Cells. Cell Death Differ (2010) 17:94251. doi: $10.1038 / \mathrm{cdd} .2009 .190$

74. Gatti G, Nuñez NG, Nocera DA, Dejager L, Libert C, Giraudo C, et al. Direct Effect of dsRNA Mimetics on Cancer Cells Induces Endogenous IFN- $\beta$ Production Capable of Improving Dendritic Cell Function. Eur J Immunol (2013) 43:1849-61. doi: 10.1002/eji.201242902

75. Salaun B, Lebecque S, Matikainen S, Rimoldi D, Romero P. Toll-Like Receptor 3 Expressed by Melanoma Cells as a Target for Therapy? Clin Cancer Res (2007) 13:4565-74. doi: 10.1158/1078-0432.CCR-07-0274

76. Goto Y, Arigami T, Kitago M, Nguyen SL, Narita N, Ferrone S, et al. Activation of Toll-like Receptors 2, 3, and 4 on Human Melanoma Cells Induces Inflammatory Factors. Mol Cancer Ther (2008) 7:3642-53. doi: 10.1158/1535-7163.MCT-08-0582

77. Aranda F, Llopiz D, Díaz-Valdés N, Riezu-Boj JI, Bezunartea J, Ruiz M, et al. Adjuvant Combination and Antigen Targeting as a Strategy to Induce Polyfunctional and High-Avidity T-cell Responses Against Poorly Immunogenic Tumors. Cancer Res (2011) 71:3214-24. doi: 10.1158/00085472.CAN-10-3259

78. Conforti R, Ma Y, Morel Y, Paturel C, Terme M, Viaud S, et al. Opposing Effects of Toll-Like Receptor (TLR3) Signaling in Tumors can be Therapeutically Uncoupled to Optimize the Anticancer Efficacy of TLR3 Ligands. Cancer Res (2010) 70:490-500. doi: 10.1158/0008-5472. CAN-09-1890

79. Amarante MK, de Oliveira KB, Guembarovski RL, da Silva do Amaral Herrera AC, Guembarovski AL, Sobrinho WJ, et al. Toll-Like Receptor 3: Implications for Proinflammatory Microenvironment in Human Breast Cancer. Mol Biol Rep (2012) 39:11087-92. doi: 10.1007/s11033-0122013-1

80. Salaun B, Zitvogel L, Asselin-Paturel C, Morel Y, Chemin K, Dubois C, et al. TLR3 as a Biomarker for the Therapeutic Efficacy of Double-Stranded RNA in Breast Cancer. Cancer Res (2011) 71:1607-14. doi: 10.1158/00085472.CAN-10-3490

81. Jia D, Yang W, Li L, Liu H, Tan Y, Ooi S, et al. $\beta$-Catenin and NF- $k b$ CoActivation Triggered by TLR3 Stimulation Facilitates Stem Cell-Like Phenotypes in Breast Cancer. Cell Death Differ (2015) 22:298-310. doi: $10.1038 /$ cdd.2014.145

82. Harashima $\mathrm{N}$, Inao $\mathrm{T}$, Imamura $\mathrm{R}$, Okano $\mathrm{S}$, Suda $\mathrm{T}$, Harada $\mathrm{M}$. Roles of the PI3K/Akt Pathway and Autophagy in TLR3 Signaling-Induced Apoptosis and Growth Arrest of Human Prostate Cancer Cells. Cancer Immunol Immunother (2012) 61:667-76. doi: 10.1007/s00262-011-1132-1

83. Paone A, Starace D, Galli R, Padula F, De Cesaris P, Filippini A, et al. TollLike Receptor 3 Triggers Apoptosis of Human Prostate Cancer Cells Through a PKC-alpha-dependent Mechanism. Carcinogenesis (2008) 29:1334-42. doi: 10.1093/carcin/bgn149

84. Palchetti S, Starace D, De Cesaris P, Filippini A, Ziparo E, Riccioli A. Transfected Poly(I:C) Activates Different dsRNA Receptors, Leading to Apoptosis or Immunoadjuvant Response in Androgen-Independent Prostate Cancer Cells. J Biol Chem (2015) 290:5470-83. doi: 10.1074/ jbc.M114.601625

85. Park J-H, Jeon D-I, Yoon H-E, Kwon S-M, Kim S-A, Ahn S-G, et al. Poly I:C Inhibits Cell Proliferation and Enhances the Growth Inhibitory Effect of Paclitaxel in Oral Sqaumous Cell Carcinoma. Acta Odontol Scand (2012) 70:241-5. doi: 10.3109/00016357.2011.640278

86. Niedzielska I, Niedzielski Z, Tkacz M, Orawczyk T, Ziaja K, Starzewski J, et al. Toll-Like Receptors and the Tendency of Normal Mucous Membrane to Transform to Polyp or Colorectal Cancer. J Physiol Pharmacol (2009) 60 Suppl 1:65-71. doi: 10.1016/j.intimp.2021.107662

87. Xiang L, Wang S, Jin X, Duan W, Ding X, Zheng C. Expression of BMP2, Tlr3, TLR4 and COX2 in Colorectal Polyps, Adenoma and Adenocarcinoma. Mol Med Rep (2012) 6:973-6. doi: 10.3892/mmr. 2012.1046

88. Takemura R, Takaki H, Okada S, Shime H, Akazawa T, Oshiumi H, et al. Polyi:C-Induced, TLR3/RIP3-Dependent Necroptosis Backs Up Immune Effector-Mediated Tumor Elimination In Vivo. Cancer Immunol Res (2015) 3:902-14. doi: 10.1158/2326-6066.CIR-14-0219

89. Hong X, Dong T, Hu J, Yi T, Li W, Zhang Z, et al. Synergistical Toll-Like Receptors Activated Dendritic Cells Induce Antitumor Effects Against 
Carcinoembryonic Antigen-Expressing Colon Cancer. Int J Colorectal Dis (2013) 28:25-33. doi: 10.1007/s00384-012-1530-7

90. Fernandez-Garcia B, Eiró N, González-Reyes S, González L, Aguirre A, González LO, et al. Clinical Significance of Toll-like Receptor 3, 4, and 9 in Gastric Cancer. J Immunother (2014) 37(2):77-83. doi: 10.1097/CJI. 0000000000000016

91. Hsu W-M, Huang C-C, Wu P-Y, Lee H, Huang M-C, Tai M-H, et al. TollLike Receptor 3 Expression Inhibits Cell Invasion and Migration and Predicts a Favorable Prognosis in Neuroblastoma. Cancer Lett (2013) 336:338-46. doi: 10.1016/j.canlet.2013.03.024

92. Morikawa T, Sugiyama A, Kume H, Ota S, Kashima T, Tomita K, et al. Identification of Toll-like Receptor 3 as a Potential Therapeutic Target in Clear Cell Renal Cell Carcinoma. Clin Cancer Res (2007) 13:5703-9. doi: 10.1158/1078-0432.CCR-07-0603

93. Samara KD, Antoniou KM, Karagiannis K, Margaritopoulos G, Lasithiotaki I, Koutala E, et al. Expression Profiles of Toll-like Receptors in non-Small Cell Lung Cancer and Idiopathic Pulmonary Fibrosis. Int J Oncol (2012) 40:1397-404. doi: 10.3892/ijo.2012.1374

94. Sheyhidin I, Nabi G, Hasim A, Zhang R-P, Ainiwaer J, Ma H, et al. Overexpression of TLR3, Tlr4, TLR7 and TLR9 in Esophageal Squamous Cell Carcinoma. World J Gastroenterol (2011) 17:3745-51. doi: 10.3748/ wjg.v17.i32.3745

95. Liu Y, Gu Y, Han Y, Zhang Q, Jiang Z, Zhang X, et al. Tumor Exosomal Rnas Promote Lung Pre-metastatic Niche Formation by Activating Alveolar Epithelial TLR3 to Recruit Neutrophils. Cancer Cell (2016) 30:243-56. doi: $10.1016 / j . c c e l l .2016 .06 .021$

96. Liu B, Wang X, Chen T-Z, Li G-L, Tan C-C, Chen Y, et al. Polarization of M1 Tumor Associated Macrophage Promoted by the Activation of TLR3 Signal Pathway. Asian Pac J Trop Med (2016) 9:484-8. doi: 10.1016/j.apjtm. 2016.03.019

97. Wu Y, Huang W, Chen L, Jin M, Gao Z, An C, et al. Anti-Tumor Outcome Evaluation Against non-Small Cell Lung Cancer In Vitro and In Vivo Using PolyI:C as Nucleic Acid Therapeutic Agent. Am J Transl Res (2019) 11:1919-37.

98. Zheng X, Li S, Zang Z, Hu J, An J, Pei X, et al. Evidence for Possible Role of TollLike Receptor 3 Mediating Virus-Induced Progression of Pituitary Adenomas. Mol Cell Endocrinol (2016) 426:22-32. doi: 10.1016/j.mce.2016.02.009

99. Pasare C, Medzhitov R. Toll-Like Receptors and Acquired Immunity. Semin Immunol (2004) 16:23-6. doi: 10.1016/j.smim.2003.10.006

100. Le Bon A, Schiavoni G, D’Agostino G, Gresser I, Belardelli F, Tough DF. Type I Interferons Potently Enhance Humoral Immunity and can Promote Isotype Switching by Stimulating Dendritic Cells In Vivo. Immunity (2001) 14:461-70. doi: 10.1016/S1074-7613(01)00126-1

101. Havenar-Daughton C, Kolumam GA, Murali-Krishna K. Cutting Edge: The Direct Action of Type I IFN on CD4 T Cells is Critical for Sustaining Clonal Expansion in Response to a Viral But Not a Bacterial Infection. J Immunol (2006) 176:3315-9. doi: 10.4049/jimmunol.176.6.3315

102. Wiesel M, Kratky W, Oxenius A. Type I IFN Substitutes for T Cell Help During Viral Infections. J Immunol (2011) 186:754-63. doi: 10.4049/ jimmunol.1003166

103. Robinson RA, DeVita VT, Levy HB, Baron S, Hubbard SP, Levine AS. A Phase I-II Trial of Multiple-Dose Polyriboinosic-Polyribocytidylic Acid in Patieonts With Leukemia or Solid Tumors. J Natl Cancer Inst (1976) 57:599_ 602. doi: 10.1093/jnci/57.3.599
104. Adams M, Navabi H, Jasani B, Man S, Fiander A, Evans AS, et al. Dendritic Cell (DC) Based Therapy for Cervical Cancer: Use of DC Pulsed With Tumour Lysate and Matured With a Novel Synthetic Clinically non-Toxic Double Stranded RNA Analogue Poly [I]:Poly [C(12)U] (Ampligen R). Vaccine (2003) 21:787-90. doi: 10.1016/S0264-410X(02)00599-6

105. Stevenson HC, Abrams PG, Schoenberger CS, Smalley RB, Herberman RB, Foon KA. A Phase I Evaluation of Poly(I,C)-LC in Cancer Patients. J Biol Response Mod (1985) 4:650-5.

106. Lampkin BC, Levine AS, Levy H, Krivit W, Hammond D. Phase II Trial of Poly(I,C)-LC, an Interferon Inducer, in the Treatment of Children With Acute Leukemia and Neuroblastoma: A Report From the Children's Cancer Study Group. J Biol Response Mod (1985) 4:531-7.

107. Sabbatini P, Tsuji T, Ferran L, Ritter E, Sedrak C, Tuballes K, et al. Phase I Trial of Overlapping Long Peptides From a Tumor Self-Antigen and polyICLC Shows Rapid Induction of Integrated Immune Response in Ovarian Cancer Patients. Clin Cancer Res (2012) 18:6497-508. doi: 10.1158/10780432.CCR-12-2189

108. Brodsky I, Strayer DR, Krueger LJ, Carter WA. Clinical Studies With Ampligen (Mismatched Double-Stranded RNA). J Biol Response Mod (1985) 4:669-75

109. Rettenmaier MA, Berman ML, DiSaia PJ. Treatment of Advanced Ovarian Cancer With Polyinosinic-Polycytidylic Lysine Carboxymethylcellulose (Poly(ICLC)). Gynecol Oncol (1986) 24:359-61. doi: 10.1016/0090-8258 (86)90313-6

110. Krown SE, Kerr D, Stewart WE, Field AK, Oettgen HF. Phase I Trials of Poly (I,C) Complexes in Advanced Cancer. J Biol Response Mod (1985) 4:640-9.

111. Misako M, Megumi T, Fumiko N, Masahiro A, Noriko I, Akiko MS, et al. Defined TLR3-specific Adjuvant That Induces NK and CTL Activation Without Significant Cytokine Production In Vivo. Nat Commun (2015) 6:6280. doi: $10.1038 /$ ncomms 7280

112. Coussens LM, Werb Z. Inflammation and Cancer. Nature (2002) 420 (6917):860-7. doi: 10.1038/nature01322

113. Pirher N, Pohar J, Manček-Keber M, Benčina M, Jerala R. Activation of Cell Membrane-Localized Toll-like Receptor 3 by Sirna. Immunol Lett (2017) 189:55-63. doi: 10.1016/j.imlet.2017.03.019

114. Matsumoto M, Funami K, Tanabe M, Oshiumi H, Shingai M, Seto Y, et al. Subcellular Localization of Toll-Like Receptor 3 in Human Dendritic Cells. J Immunol (2003) 171:3154-62. doi: 10.4049/jimmunol.171.6.3154

115. Murakami Y, Fukui R, Motoi Y, Kanno A, Shibata T, Tanimura N, et al. Roles of the Cleaved N-Terminal TLR3 Fragment and Cell Surface TLR3 in Double-Stranded Rna Sensing. J Immunol (2014) 193:5208-17. doi: 10.4049/ jimmunol.1400386

Conflict of Interest: The authors declare that the research was conducted in the absence of any commercial or financial relationships that could be construed as a potential conflict of interest.

Copyright $\odot 2021$ Zheng, Li and Yang. This is an open-access article distributed under the terms of the Creative Commons Attribution License (CC BY). The use, distribution or reproduction in other forums is permitted, provided the original author(s) and the copyright owner(s) are credited and that the original publication in this journal is cited, in accordance with accepted academic practice. No use, distribution or reproduction is permitted which does not comply with these terms. 